www.czasopisma.marszalek.com.pl/pl/10-15804/npw

\author{
Karolina Mazurowska \\ SWPS Uniwersytet Humanistycznospołeczny \\ ORCID: https://orcid.org/0000-0003-0914-1144 \\ Marta PENCZEK-ZAPA $\leftarrow$ A
ORCID: https://orcid.org/0000-0001-8783-5171
}

\title{
Dobrostan psychiczny studentów chińskich na uniwersytetach macierzystych a studentów w Polsce. Porównania międzykulturowe
}

\section{Well-being of Chinese University Students in China and Students in Poland. Cross-Cultural Comparisons}

\section{Abstract}

Presented paper discusses well-being of Chinese university students in the context of mental health issues arising on many campuses around China. The analysis focuses on self-esteem and cultural values of Chinese students in comparison with their Polish colleagues. The discussed data was collected in SUSTech, one of the developing universities in the southern part of China and in Poland. Mental health of university students has major implications for, still developing, campus health services.

Keywords: psychological well-being, students in China and Poland, cross-cultural comparative analysis 


\section{Психическое благополучие китайских студентов в китайских университетах и студентов в Польше. Межкультурный сравнительный анализ}

\section{Аннотация}

В статье обсуждается благополучие студентов китайских университетов в контексте проблем психического здоровья, возникающих во многих университетских городках по всему Китаю. В центре внимания анализа - самооценка и культурные ценности китайских студентов по сравнению с их польскими коллегами. Рассматриваемые данные были собраны в SUSTech - одном из развивающихся университетов южной части Китая, а также в Польше. Психическое здоровье студентов университетов имеет серьезные последствия для служб здравоохранения кампуса, которые все еще развиваются.

Ключевые слова: психологическое благополучие, студенты в Китае и Польше, межкультурный сравнительный анализ

$\mathrm{P}$ rezentowany artykuł dotyczy aktualnego tematu, jakim jest dobrostan psychiczny studentów chińskich uniwersytetów i związanych z nim wartości kulturowych. Przedstawiona zostanie analiza korelatów dobrostanu psychicznego i postrzeganych wartości młodych Chińczyków w odniesieniu do danych zebranych wśród polskich studentów wyższej uczelni w Polsce ${ }^{1}$.

Szereg współcześnie przeprowadzanych badań wśród chińskiej młodzieży opisuje problemy psychologiczne w świetle gwałtownych zmian zachodzących w społeczeństwie Państwa Środka. Dane statystyczne pokazują obraz pogarszającego się zdrowia psychicznego wśród badanych w wieku 17-29 lat (Yip, 2008, s. 32), czego przykładem są statystyki samobójstw czy stanów depresyjnych (Zhong, Chiu, Conwell, 2016). Czynnikiem wpływającym na tak pesymistyczne dane statystyczne jest ogromna presja społeczna, wysokie oczekiwania co do konieczności dostosowania się do istniejącej struktury społecznej, konieczność trzymania się przyjętych norm społecznych i reguł

1 Prezentowane badanie jest częścią szerszego projektu międzynarodowego, uwzględniającego postrzegane wartości i poczucia własnej wartości w kulturach polskiej, hiszpańskiej, ukraińskiej i chińskiej (Paweł Boski, Marta Penczek-Zapała, Karolina Mazurowska, Uniwersytet SWPS; Nerea Hernaiz Agreda, Carmen Carmona, University de Valencia, Hiszpania oraz Olga Lozova, University of Kiev, Ukraine). 
zachowania we wspólnocie, a także silny nacisk na edukację (Law, Liu, 2008, s. 82). Brak wolnego czasu i skomplikowane egzaminy, m.in. gaokao, wpływają na zdrowie psychiczne chińskiej młodzieży. Winne są tu także wysokie oczekiwania rodziców, dziadków wobec młodego człowieka, a w konsekwencji presja, jaką nakłada on na siebie samego (Ting, Xu, Li, Li, 2017, s. 1). Kolejnym czynnikiem kulturowym, który może przyczyniać się do zachwiania dobrostanu psychicznego, opisywanego w tym artykule w kontekście poczucia własnej wartości, jest zjawisko zachowania twarzy w społeczeństwach azjatyckich (Chinese Culture Connection, 1987). Utratę twarzy przyrównuje się do „wykluczenia” ze społeczeństwa, czyli niemożliwości skutecznego funkcjonowania w nim. Elementem utraty twarzy może być na przykład porażka na egzaminach, nieradzenie sobie z wyzwaniami na uczelni, uleganie presji konkurencji itp. Zasady dotyczące „twarzy” odnoszą się do poczucia kolektywnej wspólnoty i są często powtarzane w codziennych relacjach z innymi: Jia chou bu ke wai yang (家丑不可外扬) - „rodzinne kłótnie nie powinny być wyjawiane na zewnątrz”, Bie diu zai jia de lian (别丢在家的脸) - „nie doprowadź do utraty twarzy naszej rodziny” (Gao, Ting-Toomey, 1998, s. 17). Norma ta wiąże się z kolejnym czynnikiem wyróżniającym społeczeństwo chińskie, jakim jest ograniczona możliwość otwartego okazywania uczuć, mówienia wprost, skutkująca wewnętrznym przeżywaniem problemów emocjonalnych. Na poziomie społecznym istotna jest kontrola emocji, zaś okazywanie gwałtownych emocji jest traktowane jako przejaw niedojrzałości i nieprzewidywalności (Gao, Ting-Toomey, 1998, s. 18). Skutkuje to brakiem otwartego dzielenia się nimi z innymi, a także wpływa na zdolność radzenia sobie ze stresem, na skłonność do depresji, do zachowań ucieczkowych, a także samobójstw. Według niektórych badaczy modernizacja, a więc urbanizacja, industrializacja i wzrost ekonomiczny, jest odpowiedzialna za rosnące statystyki samobójstw w Chinach (Zhong, Chiu, Conwell, 2016, s. 2). Ponadto młodzi Chińczycy uzależniają się coraz bardziej od nowych technologii, „zanurzają się” w wirtualny świat (Jiang, 2019), co zwiększa samotność i poczucie izolacji (Huang, 2014).

Młodzi ludzie w Chinach przeżywają aktualnie stres związany z gwałtownie postępującą transformacją kraju - na przykład wyjeżdżając na studia $\mathrm{z}$ dala od domu, ale też zmuszeni wysoką konkurencyjnością na rynku, wcześnie podejmują działalność zarobkową, a zarobione pieniądze wysyłają 
rodzinie (Zhang, Wang, Xia, Liu, Jung, 2012, s. 687). Co więcej, szybko zachodzące zmiany społeczne i gospodarcze mogą powodować ryzyko zachowań samobójczych u studentów. Na przykład szybkie tempo życia, nierealistycznie wysokie ceny mieszkań, relatywnie niskie zarobki po ukończeniu studiów, wysoka konkurencyjność i postrzegana niesprawiedliwość społeczna determinują stan psychiczny ludzi młodych. Problemy z radzeniem sobie ze stresem zaczynają się u młodych Chińczyków już na poziomie rodziny - badania pokazują, że nadopiekuńczość ze strony rodziców ma związek z poczuciem bezradności po zakończeniu szkoły. W dziecięcych latach są oni wychowywani jako „mali cesarze”, zaś wraz z początkiem samodzielnego życia brakuje im efektywnych metod radzenia sobie z problemami, które rozwiązywali za nich rodzice. Może to generować stres i zwiększyć ryzyko problemów psychologicznych w okresie późniejszym (Zhang, Wang, Xia, Liu, Jung, 2012, s. 688). Z kolei Chińczycy często nie zwracają się do psychiatry lub terapeuty z prośbą o pomoc, ponieważ nie uważają, iż depresja czy myśli o samobójstwie stanowią element dysfunkcji psychicznych. Potoczne myślenie sugeruje przeciwną interpretację - młodzi ludzie traktują te zjawiska jako zwykłe przemęczenie i uleganie trudnościom życiowym (Jie, Jia, 2015, s. 9).

\section{Poczucie własnej wartości jako potencjał jednostki a wartości kulturowe}

Obszarem badawczym w prezentowanym artykule jest międzykulturowa psychologia wartości i dobrostanu psychicznego, rozumianego jako poczucie własnej wartości.

Wizerunek, który stworzymy na użytek własny lub innych osób „warunkuje nasze działania społeczne, zawodowe, kształtuje relacje $\mathrm{z}$ innymi ludźmi, jak również z samym sobą, a także prowadzi do bardzo konkretnych sposobów reagowania emocjonalnego i poznawczego" (Łaguna, Lachowicz-Tabaczek, Dzwonkowska, 2007). M. Rosenberg zaproponował koncepcje samooceny jako pozytywnej lub negatywnej postawy wobec Ja, jako rodzaj globalnej oceny siebie. Podkreślał on, że wysoka samoocena w jego ujęciu oznacza przekonanie, że jest się „wystarczająco dobrym”, wartościowym człowiekiem, zaś niska samoocena oznacza niezadowolenie z siebie, odrzucenie własnego Ja (Łaguna, Lachowicz-Tabaczek, Dzwonkowska, 2007, s. 165). 
Dlatego na potrzeby tego artykułu będzie ona traktowana jako element dobrostanu psychicznego.

Od wielu lat jesteśmy świadkami dyskusji na temat uniwersalizmu konstruktu psychologicznego, jakim jest wzmacnianie siebie (self-enhancement), które prowadzi do zwiększenia poczucia własnej wartości (self-esteem) ${ }^{2}$. Wielu badaczy koncentrowało się na analizie wartości kulturowych, które mają związek z postrzeganiem swojego ja w aspekcie kulturowym, np. H. Triandis i inni (1990), H. Markus i S. Kitayama $(1991,2016)^{3}$. Rozważania S. Heine i współpracowników skupiają się na dystynktywnych cechach kultur azjatyckich, w których ochrona twarzy (protecting one's face) wzmacniana skromnością (modesty) i samokrytyką (self-criticism) pomagają w zachowaniu społecznej harmonii (Heine, Hamamura, 2007). Nie są one nieobecne w kulturach zachodnich, jednak przypisuje się im mniejszą wartość niż w kulturach Azji Wschodniej, wypływających z dziedzictwa konfucjańskiego.

Shalom Schwartz w swoich badaniach międzykulturowych dodał wymiar osobisty, związany z motywacyjną teorią wartości (Boski, 2009, s. 189). W jego ujęciu wartości definiowane są jako „poznawcza reprezentacja (zwykle przekonanie) motywacyjnego, godnego pożądania, ponadsytuacyjnego celu" (Schwartz, 1992 za: Cieciuch, 2013, s. 23).

Kontinuum wartości ma kształt koła, co oznacza, że zasada podobieństwa sąsiadujących wartości zostaje uzupełniona o zasadę niezgodności wartości przeciwległych, leżących po przeciwnej stronie koła. Niezgodność oznacza tu trudności lub niemożliwości jednoczesnej realizacji tych wartości w jednym działaniu, a także sprzeczne psychologiczne i realne konsekwencje realizacji tych wartości.

Wczesne analizy S. Schwartza przeprowadzone w Chinach (2004) pokazują wysokie wyniki przedstawicieli tej kultury w skali hierarchii (władzy) i mistrzostwa (które odnosi się do osiągnięć, ambicji i wywierania wpływu), a bardzo niskie w egalitaryzmie. Bardzo niskie pozycje zajmują Chińczycy

2 Debata prowadzona na ten temat w latach 2003-2005 na łamach JPSP pomiędzy Stevenem J. Heine i Constantinem Sedikidesem.

${ }^{3}$ Dotyczyła ona koncepcji ja niezależnego vs. ja współzależnego. 
także w wymiarach harmonii (bycie blisko z naturą, ochroną środowiska) i autonomii (obejmującej hedonizm, świat pełen wrażeń i podmiotowość) (Boski, 2009, s 189). Tego rodzaju zestawienie wartości leży u podstaw rozwoju cywilizacyjnego państw Azji Wschodniej. „Polska jest na tej mapie bliżej bieguna zakorzenienia (które obejmuje konformizm, tradycję i bezpieczeństwo) niż autonomii. Znajdujemy się relatywnie bliżej bieguna harmonii niż mistrzostwa oraz hierarchiczności niż egalitaryzmu” (Boski, 2009, s. 188), a więc jedynie $\mathrm{w}$ tym ostatnim aspekcie kultura polska jest podobna do chińskiej. Opisywane wartości są to wartości kulturowe, natomiast w badaniach na poziomie indywidualnym wartości są pogrupowane w cztery typy, tj. przekraczanie siebie (self transcendence), zachowawczość (conservation), umacnianie siebie (self-enhancement), które prowadzi do większego poczucia własnej wartości (self-esteem) oraz otwartość na zmianę (openess to change) (Cieciuch, 2013, s. 24).

\section{Emocjonalne, osobowościowe i kulturowe korelaty samooceny}

Samoocena wykazuje związki zarówno z wymiarami funkcjonowania emocjonalnego, jak i z dyspozycjami osobowościowymi, a także, jak pokazują badania S.J. Heine, jest moderowana przez wartości kulturowe (Heine, Hamamura, 2007).

We wczesnych badaniach M. Rosenberga (1965) uzyskano ujemne korelacje pomiędzy poziomem samooceny a lękiem, depresją i anomią ${ }^{4}$. Nowsze badania potwierdzają dodatnią korelację między wysoką samooceną a szczęściem (satysfakcją z życia) (Diener i Diener, 1995 za: Łaguna et. al. 2007, s. 165). Z kolei wyniki innych badań wykazały, że samoocena silnie wiąże się z pozytywnym i negatywnym afektem ${ }^{5}$, a ponadto pozostaje $\mathrm{w}$ silnych ujemnych związkach z neurotycznością oraz depresyjnościąa

Jeśli chodzi o funkcjonowanie społeczne, to rezultaty badań są zgodne co do związku samooceny z przekonaniem o własnej skuteczności

${ }^{4}$ Odpowiednio $(r=-0,64)$, depresją $(r=-0,54)$ i anomią $(r=-0,43)$.

5 Odpowiednio pozytywnym $(r=0,62)$ i negatywnym $(r=-0,53)$ afektem mierzonym skalą PANAS, za Łaguna, M. Skala samooceny..., s. 165.

6 Odpowiednio z neurotycznością $(r=-0,69)$ mierzoną skalą NEO-PI-R oraz depresyjnością $(r=-0,67)$. 
i wewnętrznym umiejscowieniem kontroli (w kulturach zachodnich), które to zmienne również odpowiadają za poziom wytrwałości i aktywności. Osoby o wysokiej samoocenie przeżywają więcej pozytywnych emocji i są bardziej aktywne oraz wytrwałe, zaś osoby o niskiej samoocenie przeżywają więcej negatywnych emocji (lęku, smutku i depresji), a nawet przybierają postawę unikową wobec trudności, wyzwania, przed jakim stają i mają tendencję do unikania ryzyka. Badania przeprowadzone w kulturach zachodnich pokazują, że osoby o wysokiej samoocenie postrzegają siebie na wielu wymiarach funkcjonowania zadaniowego i społecznego bardziej pozytywnie niż osoby o niskiej samoocenie (Łaguna, Lachowicz-Tabaczek, Dzwonkowska, 2007, s. 165). Inne badania na ten temat pokazywały, że samoocena uczestników spadała, gdy tylko wyobrażali sobie swoje zachowania, w czasie których mogliby zostać wykluczeni lub odrzuceni przez kogoś innego, np. w czasie ściągania na egzaminie czy spowodowania wypadku komunikacyjnego. Dlatego też uważa się, że osoby będą zachowywać się tak, aby chronić swoją samoocenę. Będą także inicjować zachowania, w efekcie których ich wartość w oczach innych wzrośnie, a przez to zwiększą się ich szanse na społeczną akceptację i niewykluczenie z własnej grupy, a tym samym wzrost poczucia własnej wartości (Leary, 1999, s. 35). Wydaje się to tym bardziej zasadne w kulturach kolektywnych, takich jak chińska, w których członkowie mają tendencję do podporządkowania swoich działań grupie (Heine, Kitayama, Lehman, 2001, s. 434). Chińczycy rozwijają, podporządkowują swoje zachowanie, osobiste potrzeby i cele oczekiwaniom osób z ich kręgu społecznego, tj. rozwijają według terminologii psychologicznej ja współzależne (Gao, Ting-Toomey, 1998). Chińczycy osiągają także dość wysokie wyniki w zakresie społecznych praktyk i wartości w skali unikania niepewności, co oznacza, że poszukują porządku, ładu i procedur z obawy przed nieprzewidywalnymi zamianami (Fu, Wu, Yang, Ye, 2004, s. 891). To z kolei może implikować niechęć do przeprowadzania zmian w normach społecznych dotyczących np. skarżenia się, otwartego okazywania emocji czy też korzystania z usług psychologów $\mathrm{w}$ radzeniu sobie ze stresem dnia codziennego i obniżającą się w związku $\mathrm{z}$ tym samooceną. 


\section{Testowane hipotezy}

Jednym $\mathrm{z}$ aspektów kultury chińskiej jest ochrona twarzy (liu mianzi 留 面子), posłuszeństwo synowskie (xiao shun 孝顺), przywiązanie do tradycji, wysoka wartość edukacji, a co za tym idzie obawa przed porażką np. w czasie studiów oraz skromność (Chinese Culture Connection, 1987). Ponadto biorąc pod uwagę silną strukturę hierarchiczną w państwach Azji Wschodniej, w tym w Chinach (House, Hanges, Javidan, Dorfman, Gupta, 2004) oraz presję społeczną wywołaną szybką modernizacją, można postawić hipotezę, że Dobrostan psychiczny studentów w Chinach rozumiany jako samoocena będzie niższy, niż studentów polskich (Hipoteza 1). Co więcej, Hipotezę 1 sugerują wcześniejsze badania nad poczuciem własnej wartości wśród Azjatów, które pokazywały niskie wyniki, wskazywały na ja dialektyczne, niestałe (inconsistent) w odpowiedziach na pozytywne i negatywne aspekty ja w skali SES Rosenberga w porównaniu do badanych Europejczyków i Amerykanów (Boucher, Peng, Shi, 2009).

W zakresie kulturowych aspektów samooceny można odnieść się do wielu badań Stevena Heine’a na temat poczucia pewności siebie w kulturach o ja współzależnym i niezależnym. Ponadto przedstawiciele kultur wschodnioazjatyckich stawiają cele grupy ponad swoje indywidualne cele i potrzeby, co wiąże się także z wynikami badań S.J. Heine i T. Hamamura (2007), które podkreślały, że wschodnioazjatyccy badani nie byli skłonni do umacniania siebie (East Asians do not self-enhance) rozumianego jako skupianie się na sobie i na własnych, indywidualnych potrzebach. Zatem Hipoteza 2 brzmi: umacnianie siebie (self enhancement) $w$ kontekście dobrostanu psychologicznego będzie najmniej preferowana wartością w grupie chińskiej.

\section{Uczestnicy i procedura badawcza}

Dane do badania wśród Chińczyków zostały zebrane przez autorki niniejszego tekstu w jednym z szybko rozwijających się uniwersytetów w południowych Chinach w Shenzhen ${ }^{7}$, zaś do próby europejskiej wśród studentów Uniwersytetu SWPS. Uczestnictwo w badaniach było anonimowe

7 Dane zostały zebrane w Southern University of Science and Technology (SUSTech) 南方科技大学, który - będąc chińskim uniwersytetem państwowym - jest jednocześnie 
i dobrowolne, oznaczeniu podlegał jedynie rok i kierunek studiów oraz płeć. W obydwu grupach badani mieli od 19 do 24 lat. Tabela 1 przedstawia liczebność osób badanych.

Tabela 1. Osoby badane

\begin{tabular}{|l|c|c|}
\hline & Kobiety & Mężczyźni \\
\hline Chiny & 40 & 72 \\
Polska & 109 & 32 \\
\hline
\end{tabular}

\section{Narzędzia badawcze}

W badaniu użyto dwóch skal przetłumaczonych na języki narodowe (do badań wykorzystano chińską wersję skali samooceny M. Rosenberga i S. Schwartza w jęz. chińskim uproszczonym). Pierwsza skala to skala poczucia własnej wartości M. Rosenberga, zaś druga to uproszczona skala wartości kulturowych S. Schwartza. Skala Rosenberga zbudowana jest z dziesięciu twierdzeń mających charakter diagnostyczny: „Posiadam wiele pozytywnych cech, mam wiele powodów, aby być z siebie dumny/dumna”; „Jestem skłonny/skłonna sądzić, że nie wiedzie mi się”, „Czasami czuję się bezużyteczny/bezużyteczna”. Osoby dokonujące samooceny wartościowały siebie w skali od oceny wyrażonej: „zupełnie się zgadzam ze stwierdzeniem” do oceny „zupełnie się nie zgadzam ze stwierdzeniem". Im większa liczba punktów, tym samoocena jest wyższa, aż do zawyżonej w przypadku punktacji oscylującej wokół 40 punktów. Natomiast liczba punktów poniżej 25 świadczy o problemach ze zbyt niską samooceną.

Ze skali Portretowego kwestionariusza wartości (Portrait Values Questionnaire, PVQ) Saloma Schwartza wybrano 30 z 57 pytań nt. wartości: przekraczanie siebie (self transcendence), zachowawczość (conservation), umacnianie siebie (self-enhancement), które prowadzi do większego poczucia własnej wartości oraz otwartość na zmianę (openess to change). Skale wykazały satysfakcjonujące rzetelności od alpha $=0,60$ do alpha $=0,84$. Skalą była 6-punktowa skala Likerta - „W jakim stopniu ten człowiek jest podobny do Ciebie?” (1) od 'zupełnie niepodobny do mnie' do 'bardzo podobny do mnie' (6).

finansowo wspierany ze środków prowincji Guandong (Shenzhen Municipal Government), a nie Ministerstwa Edukacji ChRL. 


\section{Wyniki badań}

Porównanie statystyk opisowych pokazało, że średnie i mediany nie różnią się w sposób istotny statystycznie pomiędzy grupą polską a chińską ( $M=4,49$ dla Polaków i $M=4,61$ dla Chińczyków). Brak różnic pomiędzy średnimi $(t(254)=-1,02, p=.31)$ oznacza, że hipoteza 1 nie została potwierdzona.

Wykres 1 i 2 przedstawia różnicę w rozkładzie odpowiedzi między grupą chińską a polską.

Na wykresach widać różnicę w rozkładach odpowiedzi w skali poczucia własnej wartości M. Rosenberga. Wbrew wcześniejszym badaniom, to wśród Chińczyków można zauważyć rozkład skrzywiony, który występował w kulturach zachodnich (wśród Azjatów rozkład był normalny). Taki rozkład normalny wyników pojawił się zaś w grupie polskiej, w której oczekiwano wyników asymetrycznych. Może to sugerować zmiany kulturowe w kierunku większej pewności siebie i lepszej samooceny w grupie chińskiej.

Ponieważ grupy są nierównoliczne ze względu na płeć, nie można określić różnic w zależności od płci osób badanych.

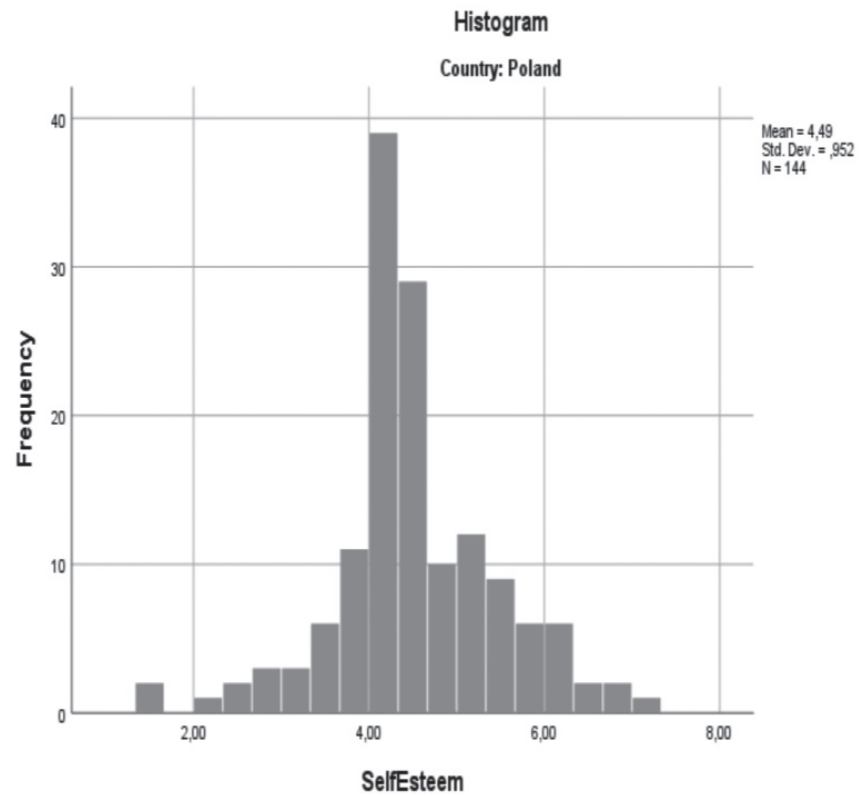

Wykres 1. Rozkład odpowiedzi dla grupy polskiej

Źródło: opracowanie własne autorek. 


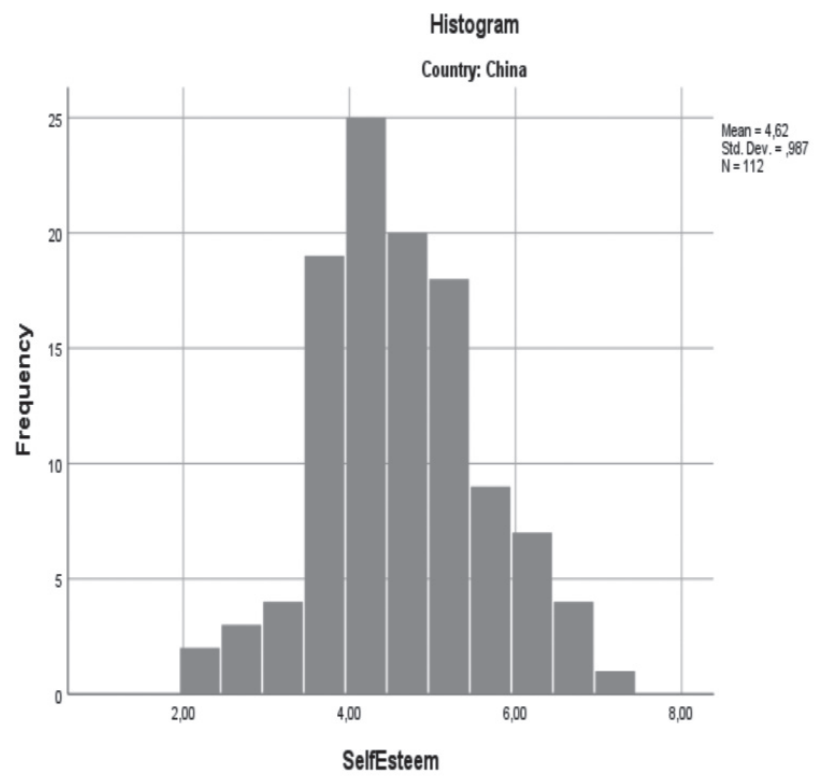

Wykres 2. Rozkład odpowiedzi dla grupy chińskiej

Źródło: opracowanie własne autorek.

Wykres 3. pokazuje preferencje wartości pomiędzy grupami polską i chińską.

6,0000

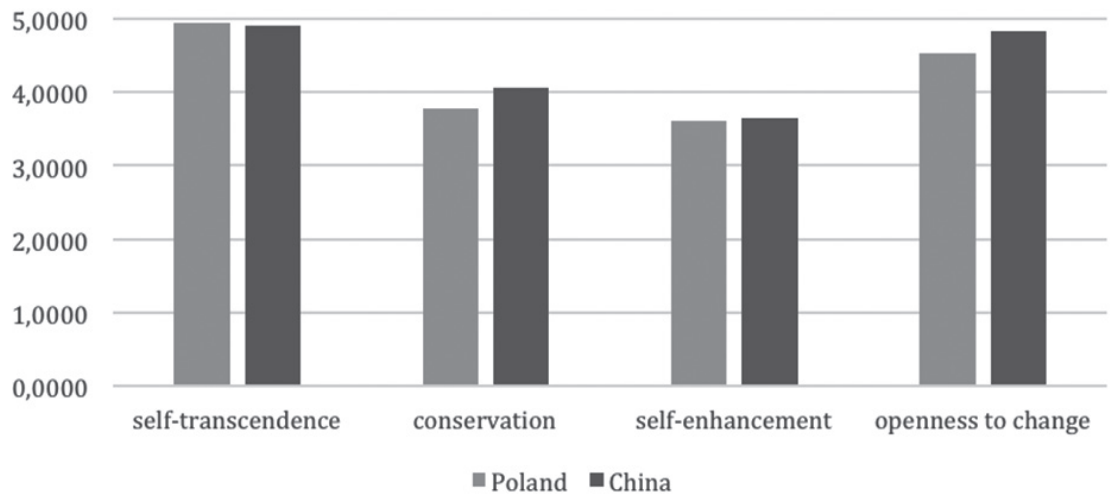

Wykres 3. Preferencje wartości pomiędzy grupami kulturowymi Źródło: opracowanie własne autorek. 
Heine i Hamamura (2007) podkreślali w swoich analizach, że wschodnioazjatyccy badani nie byli skłonni do umacniania siebie (Self-enhancement) rozumianego jako skupianie się na sobie i na własnych, indywidualnych potrzebach. Powyższa analiza częściowo potwierdziła hipotezę 2 - Chińczycy najmniej preferowali tę wartość, co ciekawe, podobnie jak Polacy. Nie ma między nimi różnic statystycznych w preferencji tej wartości, podobnie jak w przypadku przekraczania siebie (Self-transcendence). Natomiast między Polską a Chinami wystąpiły statystyczne różnice w zakresie różnic między średnimi w przypadku skali otwartości na zmianę (Openess to change) oraz zachowawczości (Conservation). Chińczycy istotnie bardziej są otwarci na zmianę oraz istotnie bardziej zachowawczy.

Poniżej przedstawiono wyniki badań korelacyjnych pomiędzy poczuciem własnej wartości a czterema wartościami kulturowymi w grupach narodowych.

Tabela 2. Wyniki korelacji pomiędzy poczuciem własnej wartości a wartościami z podziałem na narodowość

\begin{tabular}{|l|l|l|}
\hline & Polska & Chiny \\
\hline $\begin{array}{l}\text { Przekraczanie siebie } \\
\text { (self-transcendence) }\end{array}$ & $-.20^{*}$ & $.19^{*}$ \\
\hline $\begin{array}{l}\text { Zachowawczość } \\
\text { (conservation) }\end{array}$ & -.05 & .16 \\
\hline $\begin{array}{l}\text { Umacnianie siebie } \\
\text { (self-enhancement) }\end{array}$ & 0 & $.24^{*}$ \\
\hline $\begin{array}{l}\text { Otwartość na zmianę } \\
\text { (openness to change) }\end{array}$ & -.02 & $.30^{* *}$ \\
\hline
\end{tabular}

Źródło: opracowanie własne autorek.

Uwagi. $N=,{ }^{* * *} p<0,001,{ }^{* *} p<0,01,{ }^{*} p<0,05$

Struktura wyników korelacyjnych ściśle zależy od kultury pochodzenia osoby badanej. W Polsce Przekraczanie siebie negatywnie koreluje z pewnością siebie, w Chinach jedynie Zachowawczość jest czynnikiem nieskorelowanym z omawianą wartością. Wśród chińskich studentów Otwartość na zmiane, Umacnianie siebie i Przekraczanie siebie są predyktorem poczucia własnej wartości (self-esteem). 


\section{Dyskusja wyników}

Badania przeprowadzone w chińskim kontekście kulturowym przedstawiają szereg ciekawych danych. Przede wszystkim chińscy studenci prezentują podobne wyniki co do samooceny z polskimi, ale rozkład wyników jest inny, upodobniony to tych przewidywanych w kulturach zachodnich. Może być to związane z przeprowadzeniem badań wśród studentów w jednym z najbardziej prestiżowych uniwersytetów w południowych Chinach, którego motto to: Badania, innowacje, przedsiębiorczość („Research, Innovation and Entrepreneurship", www.sustech.edu.cn.) $)^{8}$.W opisywanej uczelni ponad $60 \%$ studentów po skończeniu studiów wyjeżdża zagranicę w celu podjęcia pracy lub dalszej nauki, zatem chęć osiągana dobrych ocen i bycia jednymi z najlepszych jest ogromna. Ponadto aktualny klimat polityczny w Chinach, sukcesy gospodarcze i polityczne mogą wzniecać wśród młodych ludzi większe poczucie pewności siebie.

Młodzi ludzie w Chinach przeżywają aktualnie stres związany z gwałtownie postępującą transformacją Chin, na przykład wyjeżdżając na studia $\mathrm{z}$ dala od domu. Wiąże się to $\mathrm{z}$ presją na dobre wyniki w nauce, a potem na znalezienie dobrze płatnej pracy. Możliwe, że opisywane badania ukazują drugi wymiar - Modernizację, którą jest otwartość na zmianę. Prawdopodobnie jej wysoki poziom uzyskany w badaniu wynika z tego, że zostało ono przeprowadzone wśród studentów, którzy są aktualnie trzecim lub czwartym pokoleniem żyjącym w permanentnej transformacji, coraz większej modernizacji, generacją, której przedstawiciele nie szczędzą wysiłków na rzecz poprawienia swojego statusu materialnego (Durvasula, Lysonski, 2010, s. 170).

W kontekście analizy korelacji pomiędzy Umacnianiem siebie a poczuciem własnej wartości można odnieść się do wymiaru Mistrzostwo, który w badaniach Schwartza wypadał wysoko w Chinach. Uwidacznia się również teraz w postaci coraz większej presji na doskonalenie się, stawanie się nr $1 \mathrm{w}$ domenie prywatnej i narodowej. Co więcej, młodzi Chińczycy na

8 Uniwersytet SUSTech jest aktualnie nr $8 \mathrm{w}$ chińskim rankingu uniwersytetów technicznych. 
co dzień zauważają efekty transformacji gospodarczej Chin ${ }^{9}$, w związku $z$ tym są otwarci na dalsze zmiany. Ponadto Shenzhen jest niezwykle nowoczesnym, bardzo szybko rozwijającym się miastem, do którego młodzież przybywa z wielu innych, biedniejszych regionów Chin. Shenzhen staje się na ich oczach i z ich udziałem nową Doliną Krzemową, centrum innowacji i rozwoju zaawansowanych technologii, w czym badany uniwersytet także bierze aktywny udział. Studenci mogą być tego świadomi, co może się wiązać z ich wyższym poczuciem wartości. Z drugiej strony nie dziwi wysoka zachowawczość chińskich osób badanych. Młodzi Chińczycy przyjeżdżają na studia do Shenzhen z wielu mniejszych, biedniejszych miejsc, przywożąc ze sobą bardziej tradycyjne cechy kultury chińskiej, zatem można powiedzieć, że Shenzhen to jednocześnie tygiel chińskości.

Podsumowując, analizowane badania dobrostanu psychicznego młodych Chińczyków pokazują, że w chińskim społeczeństwie następują daleko idące zmiany wewnętrznego Ja studentów, które przybierają postać znaną z badań zachodnich - Ja umacnianego, Ja otwartego na zmiany. Należałoby jednak dalej zbadać, jakie koszty psychiczne ta modernizacja pochłania oraz zadbać o zapewnienie studentom wsparcia, które stałoby się punktem wyjścia do tworzenia lepszych warunków do rozwoju na uczelni i w dalszej pracy zawodowej. Sugestia ta jest szczególnie aktualna także w kontekście wyniku polskich studentów uczestniczących w badaniu.

\section{DR KAROLINA MAZUROWSKA}

Wydział Psychologii

SWPS Uniwersytet Humanistycznospołeczny

ul. Chodakowska 19/31,03-815 Warszawa

kmazurowska@swps.edu.pl

DR MARTA PENCZEK-ZAPAŁA

marta.penczek@gmail.com

9 Gospodarka Chin jest od dziesięcioleci najprężniej rozwijającą się na świecie. Pod względem wielkości zajmuje drugie miejsce, zaraz po Stanach Zjednoczonych. Do 2030 roku rząd ChRL stawia sobie za cel wyprzedzić USA pod względem gospodarczym (por. Góralczyk, 2018; Marszałek-Kawa, 2016). 


\section{Bibliografia}

Anderson, C.A. (1999). Attributional style, depression, and loneliness: A cross-cultural comparison of American and Chinese students. Personality and Social Psychology Bulletin, 25, 482-499.

Boski, P. (2009). Kulturowe Ramy Zachowań Społecznych. Podręcznik Psychologii Międzykulturowej. Warszawa: Wydawnictwo Naukowe PWN, Academica Wydawnictwo SWPS.

Boucher, H.C., Peng, K., Shi, J. (2009). Culture and Implicit Self-Esteem: Chinese Are "Good" and "Bad" at the Same Time. Journal of Cross-Cultural Psychology, 1. Pobrane z: https://doi.org/10.1177/0022022108326195.

Chan, Y.M. (2000). Self-esteem: A cross-cultural comparison of British-Chinese, White British, and Hong Kong Chinese children. Educational Psychology, 20, 59-74.

Chinese Culture Connection (1987). Chinese values and the search for culture-free dimensions of culture. Journal of Cross-Cultural Psychology, 18, 143-164. doi:10.11 77/0022002187018002002.

Chen, J., Lian, R. (2015). Generational differences in work values in China. Social Behavior and Personality: An International Journal, 43(4), 567-578.

Cieciuch, J. (2013). Pomiar wartości w zmodyfikowanym modelu Shaloma Schwartza. Psychologia Społeczna, 8 (24). Pobrane z: http://www.spoleczna.psychologia.pl/ pliki/2013_1/Cieciuch_PS_1_2013.pdf.

Cieciuch, J., Zaleski, Z. (2011). Polska adaptacja Portretowego Kwestionariusza Wartości Shaloma Schwartza. Czasopismo Psychologiczne, 17 (2), 251-262.

Chung, T., Mallery, P. (1999). Social comparison, individualism-collectivism, and self-esteem in China and the United States. Current Psychology, 18, 340-352.

Diener, E., Diener, M. (1995). Cross-cultural correlates of life satisfaction and self-esteem. Journal of Personality and Social Psychology, 68, 653-663.

Durvasula, S., Lysonski, S. (2010) Money, money, money - how do attitudes toward money impact vanity and materialism? - the case of young Chinese consumers. Journal of Consumer Marketing, 27(2), 169-179. https://doi.org/10.1108/07363761011027268.

Fu, P.P., Wu, R., Yang, Y., Ye, J. (2004). Chinese Culture and Leadership. W: R.J. House, P.J. Hanges, M. Javidan, P.W. Dorfman, V. Gupta. Leadership, Culture and Organizations. The GLOBE study of 62 societies (877-909). Thousand Oaks, CA: Sage.

Gao, G., Ting-Toomey, S. (1998). Communicating Effectively with the Chinese. Thousand Oaks, CA: Sage.

Góralczyk, B. (2018). Wielki renesans. Chińska transformacja i jej konsekwencje. Warszawa: Wydawnictwo Akademickie Dialog.

Heine, S.J., Kitayama, S., Lehman, D.R. (2001). Cultural differences in self-evaluation: Japanese readily accept negative self-relevant information. Journal of Cross-Cultural Psychology, 32, 434-443.

Heine, S.J. (2001). Self as a product of culture. An examination of East Asian and North American selves. Journal of Psychology, 69, 881-906.

Heine, S.J., Hamamura, T. (2007) In Search of East Asian Self-Enhancement. Personality and Social Psychology Review, 11(1), 4-27. https://doi.org/10.1177/108886 8306294587. 
Heine, S.J., Lehman, D.R., Markus, H.R., Kitayama, S. (1999). Is there a universal need for positive self-regard? Psychological Review, 106, 766-794.

Hetts, J.J., Sakuma, M., Pelham, B.W. (1999). Two roads to positive regard: Implicit and explicit self-evaluation and culture. Journal of Experimental Social Psychology, 35, 512-559.

Hofstede, G. (1991). Culture and Organizations. Software of the mind. London: McGrow Hill.

House, R.J., Hanges, P.J., Javidan, M., Dorfman, P.W., Gupta, V. (2004). Culture, Leadership, and Organizations: The GLOBE Study of 62 Societies. Thousand Oaks: Sage Publications.

Huang H. (red.). (2014). Understanding China - Social Media Generation in Urban China. A Study of Social Media Use and Addiction among Adolescents. Berlin-Heidelberg: Springer-Verlag.

Kitayama, S., Uchida, Y. (2003). Explicit self-criticism and implicit self-regard: Evaluating self and friend in two cultures. Journal of Experimental Social Psychology, 39, 476-482.

Kramer, N.C., Winter, S. (2008). Impression management 2.0. The relationship of self-esteem, extraversion, self-efficacy, and self-presentation within social network sites. Journal of Media Psychology, 20(3), 106-116.

Jiang, Q. (2019). Internet Addiction Among Cyberkids in China: Risk Factors and Intervention Strategies. Springer: Berlin-Heidelberg: Verlag.

Lam, L., Peng, Z., Mai, J., Jing, J. (2009). Factors associated with Internet addiction among adolescents. CyberPsychology \& Behavior, 12(5), 551-555.

Law, S., Liu, P. (2008). Suicide in China: Unique demographic patterns and relationship to depressive disorder. Current Psychiatry Reports, 10(1), 80-86.

Leary, M.R. (1996). Self-presentation: Impression management and interpersonal behavior. Boulder: Westview Press.

Leary, M.R. (1999). Making sense of self-esteem. Current directions in Psychological Science, 8(1), 32-35. https://doi.org/10.1111/1467-8721.00008.

Lee, Y.T., Seligman, M.E. (1997). Are Americans more optimistic than the Chinese? Personality and Social Psychology Bulletin, 23, 32-40.

Leung, L. (2008). Leisure boredom, sensation seeking, self-esteem, addiction symptoms and patterns of mobile phone use. W: E. Korini, S. Utz, M. Tanis, S.B. Barnes (red.). Mediated interpersonal communication. New York: Routledge.

Li, X., Li, Z., Xie, W. (2006). Epidemiological investigation on Internet addiction among middle school students in Hefei. Chinese Mental Health Journal, 20, 51-54.

Lin, C., Lin, S., Wu, C. (2009). The effects of parental monitoring and leisure boredom on adolescents' Internet addiction. Adolescence, 44(176), 993-1004.

Łaguna, M., Lachowicz-Tabaczek, K., Dzwonkowska, I. (2007). Skala samooceny SES Morrisa Rosenberga - polska adaptacja metody. Psychologia Społeczna. Tom 2, 02(04), 164-176.

Marsh, H.W. (1996). Positive and negative global self-esteem: A substantively meaningful distinction or artifacets? Journal of Personality and Social Psychology, 70, 810-819.

Marszałek-Kawa, J. (red.). (2016). Perspektywy i bariery rozwoju chinskiej gospodarki. Toruń: Wydawnictwo Adam Marszałek. 
The Morris Rosenberg Foundation (2006). The Rosenberg Self-Esteem Scale. Pobrane z: http://www.bsos. umd.edu/socy/grad/socpsy_rosenberg.html

Nisbett, R. E., Peng, K., Choi, I., Norenzayan, A. (2001) Culture and systems of thought: Holistic vs. analytic cognition. Psychological Review, 108, 291-310.

Pyszczynski, T., Greenberg, J., Solomon, S. (2004). Why do people need self-esteem? A theoretical and empirical review. Psychological Bulletin, 130, 435-468.

Rosenberg, M. (1965). Society and adolescent self-image. New York: Princeton University Press.

Rosenberg, M. (1989). Society and adolescent self-image. Revised edition. Middletown, CT: Wesleyan University Press.

Schwartz, S.H. (2006b). A theory of cultural value orientations: Explication and applications. Comparative Sociology, 5, 137-182.

Schwartz, S.H. (2012). An Overview of the Schwartz Theory of Basic Values. Online Readings in Psychology and Culture, 2(1). https://doi.org/10.9707/2307-0919.1116.

Sedikides, C., Gaertner, L., Toguchi, Y. (2003). Pancultural self-enhancement. Journal of Personality and Social Psychology, 84, 60-79.

Singelis, T.M., Bond, M.H., Sharkey, W.F., Lai, S.Y. (1999). Unpackaging culture's influence on self-esteem and embarrassability: The role of self-construals. Journal of Cross-Cultural Psychology, 30, 315-331.

Ting, A., Xu, Q., Li, X., Li, D. (2017). Interparental Conflict and Chinese Adolescents' Suicide Ideation and Suicide attempts: The Mediating Role of Peer Victimization, Journal of Child and Family Studies, 7, 1-16.

Yang, K.-S. (2006). Indigenous Personality Research. The Chinese Case. W: U. Kim, K.-S. Yang, K.-K. Hwang (red.). Indigenous and Cultural Psychology. Understanding People in Context. Berlin: Springer, 285-314.

Yamaguchi, S., Greenwald, A.G., Banaji, M.R., Murakami, F., Chen, D., Shiomura, K. (2007). Apparent universality of positive implicit self-esteem. Psychological Science, 18, 498-500.

Yip, P.S.F. (2008). Suicide in Asia: Causes and Prevention, Hong Kong University Press, 32.

Zhang, J., Norvilitis, J.M. (2002). Measuring Chinese psychological well-being with Western developed instruments. Journal of Personality Assessment, 79, 492-511.

Zhang, J., Jia, C. (2015). Confucian Values, Negative Life Events, and Rural Young Suicide with Major Depression in China, OMEGA - Journal of Death and Dying.

Zhang, X., Wang, H., Xia, Y., Liu, X., Jung, E. (2012). Stress, Coping and Suicide Ideation in Chinese College Students, Faculty Publications, Department of Child, Youth, and Family Studies, 79.

Zhong, B.-L., Chiu, H.F.K., Conwell, Y. (2016). Elderly suicide trends in the context of transforming China, 1987-2014, Scientific Reports, 6. 